\title{
Process-based knowledge management system for continuous improvement in a corporate environment
}

\author{
Saja Mohamed Murad Al \\ Balushi \\ Halima Said Rashid Al Adawi \\ Azza Qais Abdullah Al Anasri \\ Jitendra Pandey
}

\author{
Middle East College \\ Middle East College \\ Middle East College \\ Middle East College
}

\begin{abstract}
The acquisition of information is a vital part of the performance of a program of knowledge management. An effective performance assessment mechanism is needed to improve the accuracy of the retrieval. There is no standard evaluation system for assessing the retrieval of information nowadays, because the evaluation developed is still technology-dependent, relying on specific elements of the search context. The laboratory-based assessment is not appropriate for evaluating the method of information retrieval, as knowledge is fluid, constantly changing and evolving. In addition, unclear querying is also an important factor in the success of knowledge-recovery systems. To improve knowledge retrieval performance, this paper proposes an evaluation mechanism using Six Sigma methodology to help developers continually control the process of knowledge retrieval.
\end{abstract}

The method employed is innovative and combines many IT fields and strategies for process improvement. The resulting approach applies to large and small organizations without the need for big IT support facilities. The approach promotes the growth of true organizations of learning. Specifically, this research involves the following tasks: A general framework for the retrieval of knowledge based on the results of the knowledge retrieval analysis is proposed; designs the system for the retrieval of knowledge using Six Sigma's Define-Measure-AnalyzeImprove-Control (DMAIC) process; and (iii) develops related technologies to incorporate the knowledge retrieval mechanism. The knowledge recovery assessment method helps program developers to easily manage the knowledge recovery system and, meanwhile, improve accuracy.

\section{Introduction}

Knowledge: is deliberate administration for the association's information the reason for that is to give esteem and meet the prerequisites. KM implies a solid relationship to the authoritative procedure and objectives that include the information on the administration which is useful for certain points that give an incentive for the association. (M.Sc, 2010).

A KMS that is efficient can support you and your business increment staff execution, customer fulfillment, and the nature of administration. In addition, in a particular association, information is the center of activity and development, in this manner one of the most important resources an organization may have.

All associations need compelling information about the executive's strategies to guarantee all the administration assignments put-away effectively and speedily. Information the board is characterized as the methodical administration of the information on an association as a benefit for making an incentive notwithstanding meeting the prerequisites and the procedures which will be taken to carry an incentive to the association. Information the board framework, then again, is the 
mechanical frameworks that an association uses to store and recover information notwithstanding improving coordinated effort and finding information that might be covered up in storehouses.

The KM hypothesis has just gone through a few phases with the focal point of the examinations moving to start with one measurement then onto the next and with associations picking different KM procedures (Nicolas, 2004, p.23). Regardless of various endeavors of organizations to install information the board frameworks (KMS) into their operational procedures, truly the achievement is uncommon and not so unmistakable true to form: the disappointment pace of $\mathrm{KM}$ activities is evaluated from 50 to 70\% (Akhavan et al., 2005, p.1).

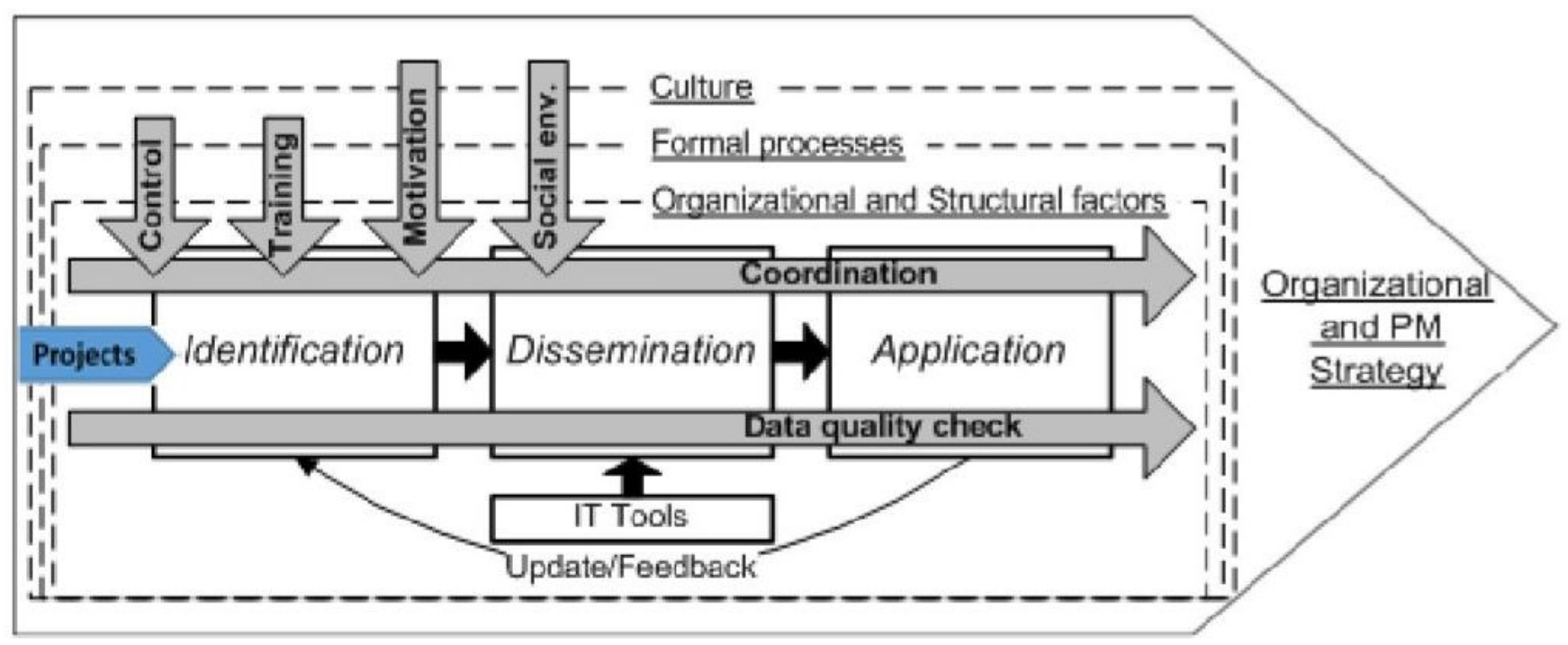

Figure 1. KMS Process

Knowledge management systems (KMS) are data frameworks utilized by organizations to share, store, control and keep up authoritative information. They are utilized to help workers in recovering, understanding and executing the put-away data. Clients can likewise include their own insight to empower associates in the association to profit by it. These aides in building compelling workgroups and making increasingly profitable and proficient associations. Figure 1 explains the KMS process and various steps involved in it.

Knowledge management is an incredibly important resource for organizations since it:

\section{Keeps up hierarchical information}

A KM protects a business's competitive innovations and information and enables clients to use it to the association's preferred position. Having a well-kept up KMS expands the focused edge of an association.

\section{Advances ceaseless learning}

A KMS urges workers to scan for the answers for issues or issues instead of alluding to an assistance work area or an administrator. This makes a persistent learning condition and creates a systematic and innovative deduction in managers. Likewise, the data age we live in makes having persistent access to data vital.

\section{Expands profitability}


As recently referenced, a KMS furnishes clients with prompt access to data, consequently the improved efficiency. On the off chance that an association KMS is well kept up and workers are all around prepared in its utilization, the business general execution will improve. KMS clients will never again be compelled to hang tight for help from an overburdened assistance work area or chief. Or maybe they will have the option to determine their very own issues productively and in an auspicious way.

\section{Empowering authoritative correspondence}

The Proposed model doesn't just interface hierarchical information yet in addition workers of the association. Clients can speak with information suppliers in the association for more data or further explanation on an issue. Inter-organizational coordinated effort and systems administration make solid and sound connections and advance collaboration.

\section{Improved Decision Making}

Different stages of the process including initial data collection, data definition, data discovery, and data quality verification. At the end of this phase, data exploration, such as viewing summary statistics (including the visual display of categorical variables) may take place. Figure 1 shows the process and how the data can be used by the KMS in assisting the decision making within organizations.

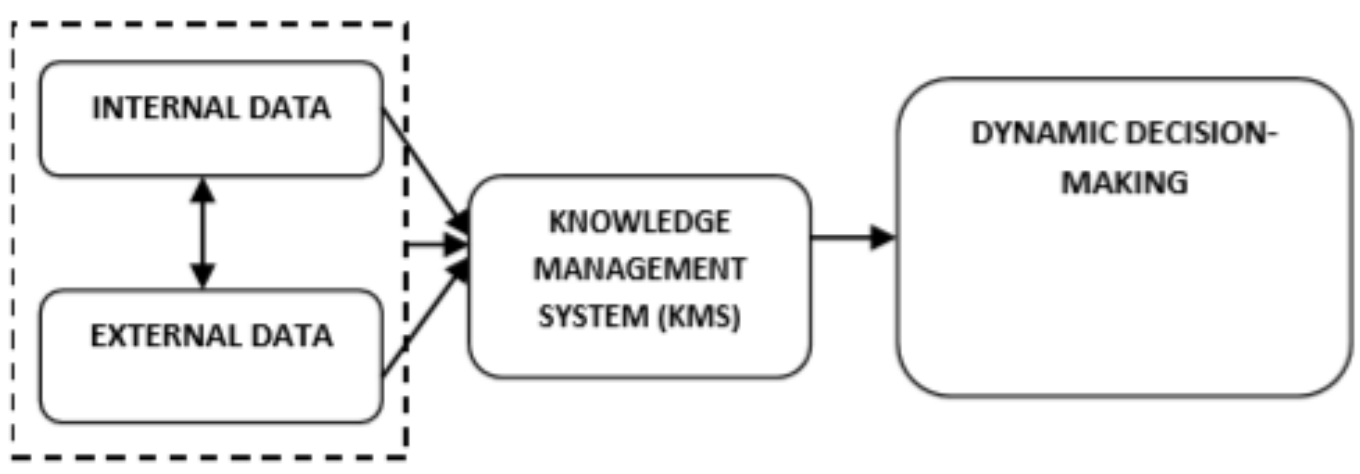

Figure 2. Improved Decision Making

\section{Gives institutionalized methodologies}

Similarly, papers and magazines pursue certain style books, a business can use a KMS to uphold a standard worldview for all representatives to pursue. This disposes of irregularities, mistaken assumptions and the pointless reiteration of guidelines in the working environment.

\section{Interfacing information}

KMS makes a commonly advantageous connection between representatives. Two representatives may enter the constrained information they each have and find that the two snippets of data supplement one another. This gives progressively thorough and comprehensive substance from which the association can profit.

In the end, a KM can profit singular divisions in an organization, yet workers themselves, and it can advance the achievement of the business in general. 


\section{Framework}

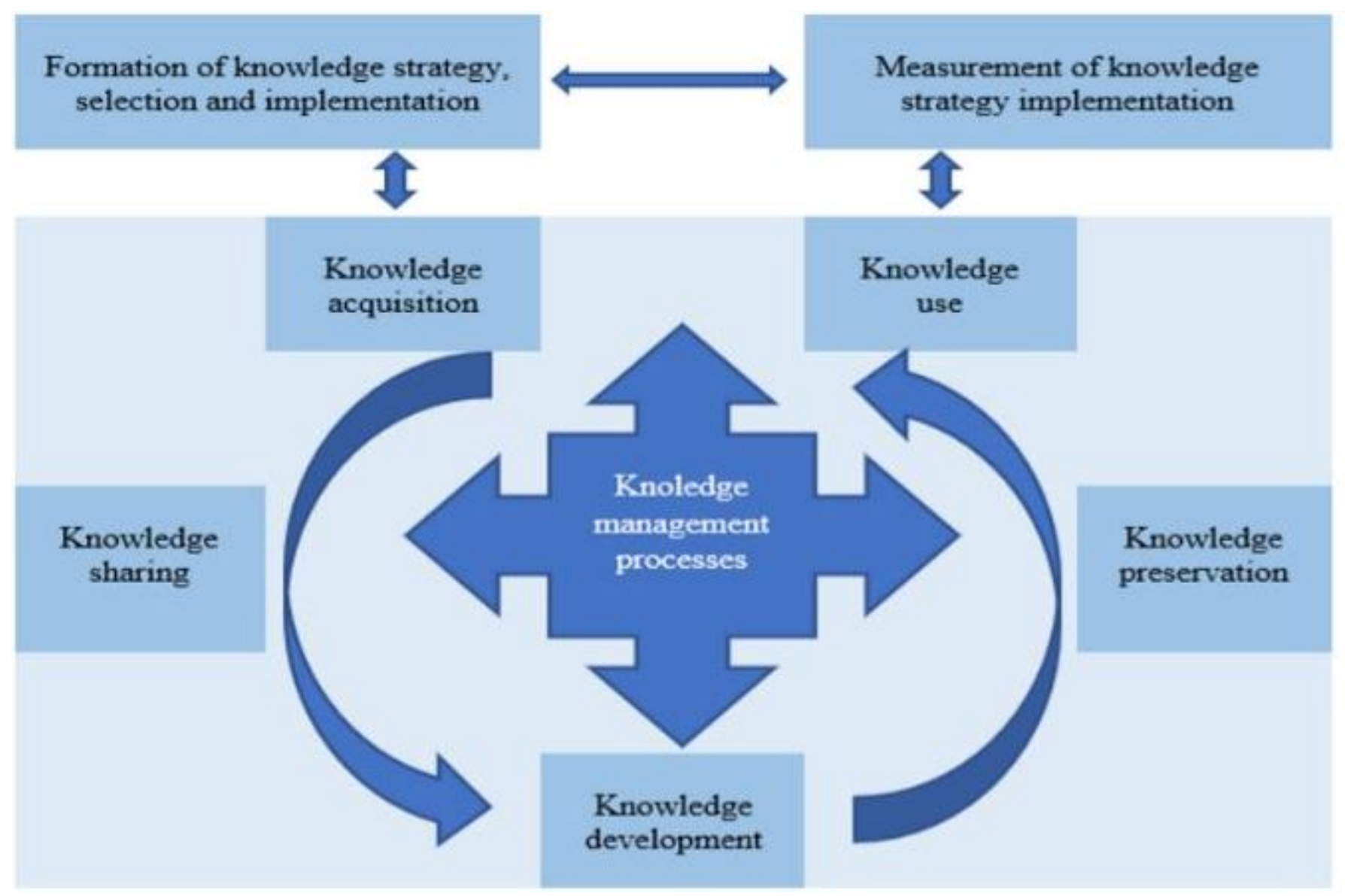

Figure 3. Knowledge Management Process Model

The figure 3 talks about the KM process involved in organizations. This talks abut knowledge sharing and knowledge acquisition, knowledge preservation and knowledge development.

The proposed framework will assist the organization in using the Knowledge effectively and helping them taking decisions.

\section{Conclusion}

The rapid advancement of Internet technology and the growing digitization and sophistication of educational activities have made the implementation of information management vital to school organizations (Richard, 2001; David, 1999; Kuo, 2003; McKenzie et al., 2001). An assessment of information the board forms depends on various methodologies, in this way it is hard to quantify information the board forms.

And the association's information potential in this investigation is characterized, as the association's assets and market openings, producing its information potential, multifaceted nature and viable administration of which make requirements for meeting the changing individual client needs, making proportional worth, uniqueness and authority in the worldwide commercial center.

\section{References}

Adams, J., Khan, H.T.A., Raeside, R. \& White, D. (2007). Research Methods for Graduate Business 


\section{Journal of Student Research}

Fourth Middle East College Student Research Conference, Muscat, Sultanate of Oman

and Social Science Students. New Delhi ; Thousand Oaks : SAGE.

Alavi, M., \& Leidner, D. E. (1999). Knowledge management systems: issues, challenges, and benefits. Communications of the AIS, 1(7), 1-37.

Akhavan, P., Jafari, M. \& Fathian, M. (2005). Exploring Failure-Factors of Implementing Knowledge Management Systems in Organizations. Journal of Knowledge Management Practice, 6, p.1-8.

Bivainis, J., \& Morkvėnas, R. (2010). Quantitative model of organization's knowledge potential assessment. In The 6th International Scientific Conference "Business and Management 2010", Selected papers (pp. 586-594). Vilnius, Lithuania

Barab, S. A., MaKinster, J. G., Moore, J. A., Cunningham, D. J., \& The ILF Design Team (2001). Designing and building an on-line community: The struggle to support sociability in the inquiry learning forum. Educational Technology Research and Development, 49, 71-96.

David, H. H. (1999). The knowledge-creating school. British Journal of Educational Studies, 47(2), 122-144.

Nissen, M. E. \& Espino, J. (2000). Knowledge Process and System Design for the Coast Guard. Knowledge and Process Management Journal, (7)3, 165-176.

Sarvary, M. (1999). Knowledge Management and Competition in the Consulting Industry. California Management Review, 41(2), 95-107.

Girish, G. P., Joseph, D., Roy, S., \& Raju, G. A. (2015). Factors influencing adoption of knowledge management systems in India from a micro, small and medium enterprise's perspective.

International Review of Management and Marketing, 5(53), 135-140.

Massingham, P. (2014). An evaluation of knowledge management tools: Part 1 - managing knowledge resources. Journal of Knowledge Management, 18(6), 1075-1100.

https://doi.org/10.1108/JKM-11-2013-0449

Yahya, S., \& Goh, W. K. (2002). Managing human resources toward achieving knowledge management. Journal of Knowledge Management, 6(5), 457-468.

https://doi.org/10.1108/13673270210450414

Kamla Ali, A., et. al. (2010). Sharing knowledge to a knowledge management system: examining the Motivators and benefits in an Omani organization. Journal of Organizational Knowledge Management, 2010, 1-12.

Han, K. H., \& Kang, J. G. (2007). A process-based performance measurement framework for continuous process improvement. International Journal of Industrial Engineering, 14(3), 220-228.

Kiessling, T. S., et. al. (2009). Exploring knowledge management to organizational performance outcomes in traditional economy. Journal of World Business, 44, 421-433. 